\title{
Screening for biomarkers reflecting the progression of Babesia microti infection
}

Bin $\mathrm{Xu}^{1+}$, Xiu-Feng Liu ${ }^{2 \dagger}$, Yu-Chun Cai ${ }^{1}$, Ji-Lei Huang ${ }^{1}$, Rui-Xiang Zhang ${ }^{2}$, Jun-Hu Chen ${ }^{1}$, Xun-Jia Cheng ${ }^{3}$, Xia Zhou ${ }^{4}$, Xue-Nian Xu', Yan Zhou', Ting Zhang ${ }^{1}$, Shen-Bo Chen', Jian Li', Qun-Feng Wu'², Cheng-Song Sun², Yong-Feng Fu', Jia-Xu Chen ${ }^{1}$, Xiao-Nong Zhou' ${ }^{1}$ and Wei Hu${ }^{1,2^{*}}$

\begin{abstract}
Background: Babesiosis is caused by the invasion of erythrocytes by parasites of the Babesia spp. Babesia microti is one of the primary causative agents of human babesiosis. To better understand the status of the disease, discovering key biomarkers of the different infection stages is crucial.

Results: This study investigated B. microti infection in the mouse model from 0 to 270 days post-infection (dpi), using blood smears, PCR assays and ELISA. PCR assays showed a higher sensitivity when compared to microscopic examination. Specific IgG antibodies could be detected from 7 days to $270 \mathrm{dpi}$. Two-dimensional electrophoresis was combined with western blotting and mass spectrometric analysis to screen for specific reactive antigens during both the peak parasitaemia period (7 dpi) and lgG antibody response peak period (30 dpi) by the infected mice plasma. The 87 positive reactive proteins were identified and then expressed with the wheat germ cell-free system. Protein microarrays of all 87 targeted proteins were produced and hybridized with the serial plasma of infected mice model. Based on the antigen reaction profile during the infection procedure, 6 antigens were selected and expressed in Escherichia coli. Due to an early response to IgM, lower immunoreactivity levels of IgG after two months and higher immunoreactivity level lgG during nine months, four recombinant proteins were selected for further characterization, namely rBm2D97(CCF75281.1), rBm2D33(CCF74637.1), rBm2D41(CCF75408.1) and rBm7(CCF73510.1). The diagnostic efficacy of the four recombinant protein candidates was evaluated in a clinical setting using babesiosis patient plasma. The rBm2D33 showed the highest sensitivity with a positive rate of $62.5 \%$. Additional characterization of the two candidate proteins using a mouse vaccination assay, demonstrated that rBm2D41 could reduce peak parasitaemia by $37.4 \%$, indicating its efficacy in preventing severe babesiosis.

Conclusions: The detection technologies of microscopic examination, PCR assays and antibody tests showed different sensitivities and accuracy during the different stages of $B$. microti infection. Antibody detection has a unique significance for B. microti infection in the asymptomatic stages. Using immunoreactivity profiles, biomarkers for disease progression were identified and represent useful information for future the diagnosis and vaccine development for this serious disease of public health significance.
\end{abstract}

Keywords: Babesia microti, Strain ATCC ${ }^{\oplus R A}$-99TM, Mice model, Cell free expression system, Protein microarray, Screening biomarker, Expression and evaluation of proteins

\footnotetext{
* Correspondence: huw@fudan.edu.cn

${ }^{\dagger}$ Bin Xu and Xiu-Feng Liu contributed equally to this work.

${ }^{1}$ National Institute of Parasitic Diseases, Chinese Center for Disease Control and Prevention, WHO Collaborating Center for Tropical Diseases; National Center for International Research on Tropical Diseases, Ministry of Science and Technology; Key Laboratory of Parasite and Vector Biology, National Health and Family Planning Commission, Shanghai, People's Republic of China

${ }^{2}$ Department of Microbiology and Microbial Engineering, School of Life

Sciences, Fudan University, Shanghai, People's Republic of China

Full list of author information is available at the end of the article
}

(c) The Author(s). 2018 Open Access This article is distributed under the terms of the Creative Commons Attribution 4.0 International License (http://creativecommons.org/licenses/by/4.0/), which permits unrestricted use, distribution, and reproduction in any medium, provided you give appropriate credit to the original author(s) and the source, provide a link to the Creative Commons license, and indicate if changes were made. The Creative Commons Public Domain Dedication waiver (http://creativecommons.org/publicdomain/zero/1.0/) applies to the data made available in this article, unless otherwise stated. 


\section{Background}

The zoonotic parasitic disease, babesiosis, is caused by the intraerythrocytic protozoans Babesia spp. Babesia spp. are usually transmitted by Ixodes ticks, blood transfusions or from mother to child transplacentally [1-3]. Among more than 100 identified Babesia species, only a few have been reported to infect humans, including Babesia microti and $B$. microti-like organisms, B. duncani and B. duncani-type organisms, $B$. divergens and $B$. divergens-like organisms, and $B$. venatorum [4-7]. Babesiosis became a nationally recognized disease in January 2011 in the USA. Babesia microti has been implicated in the majority of clinical cases in the USA; including both tick-borne and transfusion-transmitted babesiosis (TTB) [8]. This is reflected in a survey of TTB over the period of 1979-2009, where B. microti was attributed as the infectious species [8]. The dynamics of parasitaemia and immune responses in the rhesus macaque model, demonstrated that even very low infectious doses can result in TTB, and the low-grade or asymptomatic parasitemia could persist for long periods [9]. Since there is a lack of a Food and Drug Administration (FDA) approved blood screening, $B$. microti has become a high-risk pathogen that is transmitted by blood transfusions in the USA [6].

Different severities and symptoms are observed in $B$. microti-infected patients. It was always asymptomatic in healthy people, but among immune-deficient patients such as people who have undergone a splenectomy, HIV infected, or elderly, the infection can relapse and potentially become lethal [6, 10-13]. Babesia microti infections in immuno-intact primates are usually self-limiting, and most clinical cases recover without intervention [14]. However, low levels of parasitaemia have been observed in rat and monkey infection models $[15,16]$. In the $B$. microti-infected CBA mice model, parasitaemia levels gradually increased and reached peak levels in the acute phase, followed by levels quickly declining and persisting with very low parasitaemia. While parasitaemia was undetectable or cleared, antibody levels peaked and entered a chronic phase [17].

In the investigation of $B$. microti infection in blood donors of nonendemic and endemic areas in the USA, higher numbers of positive samples were detected using antibodies when compared to the use of PCR methods [18]. However, the risk of TTB for antibody-positive donors was confirmed and highlighted, no matter if they were PCR-positive or not [19]. From these observations, it is clear that antibody testing is crucial for the screening of the cases infected by B. microti. Further study of B. microti-related protective immune mechanisms, indicated that IgM antibodies first showed a response against the parasite in the acute phase and that specific IgG antibodies were related to decrease parasitaemia in the blood [17, 20-22]. However, the immunoreactivity profiles of $B$. microti infection during the acute to chronic phase remain unclear. Thus, it would be important to find the biomarkers for detection of the disease progression and identify the key antigens related to immune protection or the self-limiting phenomenon in immune-intact individuals.

In the current study, the $B$. microti-infected mice model was established, and specific reactive antigens identified during the peak parasitaemia period, also antibody levels were analyzed and expressed. A high-throughput proteomic analysis was then carried out to obtain immunoreactivity profiles. Finally, candidate molecules were screened for use as clinical diagnostics, and as potential vaccines evaluated in an animal model.

\section{Methods}

\section{Sample collection}

Eight plasma samples were collected from patients with babesiosis from Fujian, Guangdong, Xinjiang provinces and Shanghai in the P.R. China. All patients were experiencing fever, and six patients had hepatosplenomegaly. All blood samples were PCR-positive, five of which were microscopically positive (Additional file 1: Table S1). Two hundred samples collected from febrile patients in Tengchong, Yunan Province, a malaria endemic area, were microscopically negative. We also collected ten patient plasma of $P$. falciparum and $P$. vivax that were diagnosed by parasitological detection (blood smears) as malaria infection from Yunnan Province. Plasma samples from unexposed individuals, used as controls, were collected in medical college at Soochow University, Zhejiang Province.

\section{Establishing the BALB/c mice model with $B$. microti}

Babesia microti strain ATCC ${ }^{\circ}$ PA-99TM, was obtained from the Institute of Laboratory Animal Sciences, Chinese Academy of Medical Sciences (CAMS). Ten female $\mathrm{BALB} / \mathrm{c}$ mice aged six weeks were inoculated with $100 \mu \mathrm{l}$ of donor blood with $1.8 \times 10^{7} \mathrm{~B}$. microti-infected erythrocytes by intraperitoneal injection. Anticoagulant blood $(200 \mu \mathrm{l})$ was collected before infection as a control. At each time point in the study, the same dose of anticoagulant blood was collected from the caudal vein of infected mice at $3,7,14,21,30,60,120,150$ and 270 days post-infection (dpi). Erythrocytes and plasma were separated from all blood samples by standard methods, for molecular detection and antigen screening and evaluation.

\section{Staining and microscopy examination}

Blood samples were extracted from mice tail tips to prepare thin smears on microscope slides every dpi until day 30 and for each time point in the study. All smears were air-dried, fixed in absolute methanol, stained with Giemsa stain (Baso, Zhuhai, China), and then counted under $\times 1000$ magnification by a bright-field microscope (Nikon, Tokyo, Japan). Five thousand erythrocytes were scanned for each sample, and the number recorded of the erythrocytes infected with $B$. microti. 


\section{Nucleic acid testing}

Genomic DNA was extracted from erythrocytes of anticoagulant blood using the DNeasy Blood \& Tissue Kit (Qiagen, Shanghai, China). A specific fragment of B. microti $18 S$ rRNA [23] was set as the detecting target fragment, and the first-round primers were CRYPTORN (5'-GAA TGA TCC TTC CGC AGG TTC ACC TAC-3') and CRYPTOFL (5'-AAC CTG GTT GAT CCT GCC AGT AGT CAT-3'). The second-round primers were Babl (5'-GTC TTA GTA TAA GCT TTT ATA CAG CG-3') and Bab4 (5'-GAT AGG TCA GAA ACT TGA ATG ATA CAT CG-3'). Nested PCR was performed in a $25 \mu$ reaction containing $5 \mu \mathrm{l}$ buffer, $2 \mu \mathrm{l}$ dNTP mixture, $1 \mu \mathrm{l}$ of each primer, $0.5 \mu$ DNA polymerase (Takara R050A PrimeSTAR, Kanagawa, Japan) and $2 \mu \mathrm{l}$ DNA template. The reactions were performed under the following conditions: the first-round amplification: $98{ }^{\circ} \mathrm{C}$ for $3 \mathrm{~min}$, followed by 35 cycles of $10 \mathrm{~s}$ at $98{ }^{\circ} \mathrm{C}, 15 \mathrm{~s}$ at $60{ }^{\circ} \mathrm{C}, 2 \mathrm{~min}$ at $68^{\circ} \mathrm{C}$, and a final extension of $68{ }^{\circ} \mathrm{C}$ for $10 \mathrm{~min}$. The second-round amplification was carried out in the same manner as the first except that the DNA template was a 1:100 dilution of the first-round PCR product and the degenerate temperature was $55{ }^{\circ} \mathrm{C}$. The PCR reactions were performed using PTC-200 PCR System (BIO-RAD). The PCR product specificity was verified by electrophoresis, sequencing and NCBI/BLASTn.

\section{Antibody level detection}

Anticoagulation blood was collected from ten infected $\mathrm{BALB} / \mathrm{c}$ mice when parasitaemia reached approximately $60 \%$. The parasites were isolated by a previously reported method [24]. Crude B. microti proteins were produced from the supernatant of purified parasites homogenized in PBS by ultrasound. Protein concentrations were determined using the Bradford method. The proteins were stored at $-20{ }^{\circ} \mathrm{C}$ until needed. Crude protein extractions were diluted in carbonic acid buffer to a final concentration of $1 \mu \mathrm{g} / \mathrm{ml}$. All of plasma samples from 10 inoculated individuals were pooled together, diluted 50-fold in PBST and incubated with HRP-conjugated goat anti-mouse IgG (Sigma-Aldrich). Absorbance of each well at $450 \mathrm{~nm}$ was measured by MTP-500 micro plate reader (Corona Electric, Ibaraki-Ken, Japan).The cut-off value was defined as the mean value plus 2.1 standard deviations (SD) of the mean optical density (OD).

\section{Preliminary screening immunogenic antigens}

Crude B. microti protein extractions $(100 \mu \mathrm{g}$ and $800 \mu \mathrm{g})$ were loaded onto analytical and preparative gels and were separated by two-dimensional electrophoresis (2-DE). Six gels were carried out simultaneously under the same conditions to keep the experiment uniform in distribution and size of protein spots. Two of the gels were treated with silver stain and the others divided into two groups to perform immunoblots.
Proteins of the same four gels were electrotransferred simultaneously to homologous hybond-C nitrocellulose membranes (GE Amersham Biosciences, Wauwatosa, USA) for $90 \mathrm{~min}$ at $220 \mathrm{~mA}$, then incubated with 3\% BSA in PBS overnight at room temperature. After blocking, membranes were washed three times in PBST, followed by incubation in $7 \mathrm{dpi}$ or $30 \mathrm{dpi}$ plasma samples (both 1:100 in PBST) and their negative control (collected before inoculation) at room temperature for $2 \mathrm{~h}$. HRP conjugated goat anti-mouse IgG (Sigma-Aldrich, St. Louis, USA, diluted 1:1000 in PBST) was added to membranes, and were developed with $\mathrm{H}_{2} \mathrm{O}_{2}$ and 3, 3'-Diaminobenzidine(DAB). Images of immunblots were acquired by Bio-Rad GS710 scanner and analyzed using Image Master Software (Amersham). Specific spots were observed on the membrane and were matched with the silver stained gels followed by identification by liquid chromatography-mass spectrometry (LC/MS-MS) as previously described [25]. The acquired mass spectra files were converted to mzXML files using software [26], and deposited in the ProteomeXchangeConsortium [27] via the PRoteomicsIDEntifications (PRIDE)v2.4.2 [28] partner repository with the dataset identifier IPX0001196000.

\section{Acquisition of immunoreactivity profiles Cloning and expression}

To efficiently clone and express the candidates (Additional file 2: Table S2), the genes were divided into gene fragments by SMART (http://smart.embl-heidelberg.de/). All genes were PCR amplified as previously reported [29]. Gene-specific primers were designed by Primer premier 5.0 and In-Fusion PCR primers using In-Fusion Primer Design Tool (Additional file 3: Table S3). The presence of a signal peptide was determined by SignalP 4.1[30] and GPI anchor determined by both GPI Modification Site Prediction [31] and PredGPI [32], were excluded from the gene expression constructs. Genomic DNA of $B$. microti was used to amplify target genes with the same amplification system as described above. The pEU-His vector (derived from pEU, CellFree Sciences, Matsuyama, Japan) linearized by double digestion with restriction enzymes XhoI and BamHI (Takara, Kanagawa, Japan) was used in a high-throughput manner as described in a previous report [33].

All successfully cloned fragments were expressed by the bilayer translation reaction method with the wheat germ cell-free (WGCF) system [34]. Babesia microti proteins were separated by sodium dodecyl sulfate polyacrylamide gel electrophoresis (SDS-PAGE) under denaturing conditions. Separated proteins were transferred to Polyvinylidene Fluoride (PVDF) membranes (Millipore, Billerica, MA, USA), followed by blocking with 3\% BSA in PBS. Penta-His antibody (Qiagen, Duesseldorf, Germany) diluted 1:2000 in PBS and the same dilution of secondary 
HRP-conjugated goat anti-mouse IgG (Pierce, Waltham, MA, USA) were used to detect His-tagged recombinant proteins. The immunoblots were stained using $\mathrm{H}_{2} \mathrm{O}_{2}$ and DAB. The results were recorded by a ScanJet 5300C Scanner (Hewlett-Packard, Palo Alto, USA).

\section{Preparing protein microarray and acquiring immunoreactivity profiles}

OPEpoxy glass slides $(75 \times 25 \mathrm{~mm})$ were used for the carrier of protein arrays (CapitalBio, Beijing, China) and Teflon fence with 12 holes $(6 \times 2$, diameter of $9 \mathrm{~mm})$, in which a protein microarray would be formed, were attached to the glass slides to prepare amine arrays. Babesia microti proteins identified by 2-DE and Bm7(CCF73510.1) from immunoscreening of cDNA library of B. microti [35] were twice spotted into a fence of the arrays and incubated for $30 \mathrm{~min}$ at room temperature. BMSA [36, 37] was amplified from $B$. microti PRA99 strain cDNA and its recombinant protein rBmSA1 was expressed in E. coli BL21(DE3) strain as the positive control. The wheat germ lysate with empty vector served as the negative control. The array was firstly blocked with $3 \%$ BSA in PBST for $2 \mathrm{~h}$ at $37{ }^{\circ} \mathrm{C}$ and incubated at different time points with the pooled plasma samples from mice (1:50 in PBST) for $1 \mathrm{~h}$ at $37{ }^{\circ} \mathrm{C}$. The reactions were visualized with Alexa Fluor 546 goat anti-mouse IgM and IgG (10 ng/ $\mu$ l, Invitrogen, Waltham, MA, USA) in PBST for $1 \mathrm{~h}$ at $37^{\circ} \mathrm{C}$ and quantified by using ScanArray Express software version 4.0 (PerkinElmer, Waltham, MA, USA) as described previously [33]. The higher response of a probed protein against the normal plasma sample was considered to be positive when the relative ratio of signal intensity (SI) was $>2.0$ as compared to the response to the infected mice plasma.

\section{Validation of effective antigens}

\section{Expression and purification of recombinant proteins}

According to the results of the protein microarray, the DNA fragments encoding 2D33, 2D41, and 2D97, Bm7 were cloned into pET42a, pSmartI (Smart Life Sciences, Changzhou, China) and pET28a vectors (primer sequences are shown in Additional file 4: Table S4) and then expressed in an E. coli BL21(DE3) strain. The recombinant proteins, 2D33 and 2D41 were both soluble when expressed and designated rBm2D33, rBm2D41. While 2D97 and Bm7 were expressed as inclusion bodies and designated as rBm2D97 and $\mathrm{rBm} 7$. rBm2D33 was purified using glutathione sepharose $4 \mathrm{~B}$ beads and rBm2D41 using His-Trap FF (GE Healthcare Life Sciences, Wauwatosa, USA). rBm2D97 and rBm7 were purified using the Micro Protein PAGE Recovery Kit (Sangon Biotech, Shanghai, China). The quantity of recombinant proteins was measured using a BCA protein assay kit (Thermo Fisher Scientific Inc, Waltham, USA). SUMO-tagged Bm2D41 was cleaved by SUMO protease
(Solarbio, Beijing, China) according to the manufacturer's instructions.

\section{Evaluation of recombinant proteins as diagnostic antigens}

The antigen-antibody reactions were evaluated using HRP-conjugated goat anti-mouse IgG (total IgG, Sigma-Aldrich) and IgM ( $\mu$-chain, Sigma-Aldrich). Responses to different time points of mice plasma samples were done by enzyme-linked immunosorbent assay (ELISA) as previously described. HRP-conjugated goat anti-human IgG (total IgG, Sigma-Aldrich) and IgM ( $\mu$-chain, Sigma-Aldrich) responses in eight babesiosis patients' plasma for sensitivity evaluation of the diagnostic protein markers was performed to evaluate the cross-reactivity of proteins to Plasmodium infection. The plasma of ten $P$. falciparum and $P$. vivax patients were used for the determination of detection specificity.

The two hundred blood samples of febrile cases from a malaria endemic area were used in this study. The DNA of blood samples were extracted and detected by nested-PCR using specific primers of $B$. microti, $P$. falciparum and $P$. vivax $[23,38,39]$. The Plasmodium genus-specific primer pair was rPLU1 and rPLU5, a second PCR amplification was carried out with species-specific primer pairs rVIV1 and rVIV2 for $P$. vivax and rFAL1 and rFAL2 for $P$. falciparum (Additional file 5: Table S5). All plasma samples described above were tested against $B$. microti antigens: rBm2D33, rBm2D41, rBm7, rBmSA1 and crude proteins. $\mathrm{rBm} 2 \mathrm{D} 97$ was uniquely detected with IgM ( $\mu$-chain) by ELISA, in which 45 plasma samples from unexposed subjects were used as negative controls. The positive cut-off value was calculated as the mean $\mathrm{OD}$ value of the normal controls plus 2 SD.

\section{Vaccination and challenge infection}

A total of 16 six-week-old female BALB/c mice were divided into four groups $(n=4)$. Purified rBm2D41 and rBm7, 50 $\mu \mathrm{g}$ emulsified in $100 \mathrm{ml}$ of Freund's complete adjuvant (Sigma-Aldrich), was inoculated into the back of the mouse by subcutaneous injection followed by two additional booster immunizations of $50 \mu \mathrm{g}$ recombinant antigens with Freund's incomplete adjuvant and PBS at 7-day intervals. The two mice control groups were set up with an adjuvant control group were PBS-immunized with Freund's adjuvant and the no immunization group control group. One week after the final booster immunization, all mice were challenged with $1 \times 10^{7} \mathrm{~B}$. microti-infected erythrocytes [40, 41]. Parasitaemia was monitored every other day for 30 days by examining Giemsa-stained smears. The antibody level was monitored at 3, 7, 14, 21 and 30 dpi by ELISA.

\section{Statistical analysis}

Parasitaemia was evaluated with the percent of infected erythrocytes. One-way analysis of variance (ANOVA), 
followed by Tukey's multiple comparison test, was used to compare the parasitaemia mean values of all variables using GraphPad Prism software, version 5.0 (GraphPad, San Diego, USA)[42]. The heatmap was drawn using the Multi-array experiment viewer $(\mathrm{MeV})$ software [43]. Hierarchical clustering analysis (HCA) was performed with $\mathrm{R}$ [44] using Ward linkage based on a distance matrix of the Pearson correlation of the samples and clustering was conducted through the hclust function in $\mathrm{R}$ using Euclidean distance[45].

\section{Results}

Dynamic changes of parasitaemia, PCR analysis and specific antibody level in BALB/c mice infected by $B$. microti

All 10 inoculated mice were infected successfully with $B$. microti. The dynamics of parasitaemia were observed by examination of thin blood smears (Fig. 1). The acute peak was detected with the average parasitaemia of $60 \%$ on Day 8 after experimental infection. After $20 \mathrm{dpi}$, few parasites were detected into the chronic stage of infection, and after $60 \mathrm{dpi}$, no parasitaemia was observed up to when the experiment was ended at $270 \mathrm{dpi}$ (Table 1). Hemolysis, deeper urine color, and decreased vitality were observed in $B$. microti-infected BALB/c mice along with the increase of parasitaemia. Babesia microti DNA was successfully amplified from erythrocytes of the ten inoculated mice from $3 \mathrm{dpi}$ to $60 \mathrm{dpi}$, only one positive was observed on $120 \mathrm{dpi}$ (Table 1).

Antibody expression was determined by reaction intensity of crude $B$. microti proteins with mouse plasma from different infected periods as determined by ELISA (Fig. 1). The detectable antibody response appeared on Day 7 in this study, which indicated that there should be a window for antibody detection. The peak antibody titers were observed on Day 21, which was 2 weeks after the seroconversion and peak parasitaemia $(7 \mathrm{dpi})$. The antibody levels gradually declined from 21 to $60 \mathrm{dpi}$ and maintained a long plateau that kept higher antibody levels up to 270 dpi. Although PCR-reactivity has no positivity after 4 months post-infection in the mouse model, antibodies are retained for a much longer period (more than 9 months post-infection).

\section{Preliminary screening of $B$. microti antigens}

To identify potential antigens, the crude $B$. microti proteins were separated on 2-DE gels (Fig. 2c, f). Each sample was subjected to triplicate runs. Upon comparison with immune blots of normal plasma (Fig. 2a, d), 4 and 51 reactive spots were displayed on the membranes hybridized with the $7 \mathrm{dpi}$ and $30 \mathrm{dpi}$ mice, respectively (Fig. 2b, e). In total, 55 localized spots that corresponded to antigenic proteins in 2-DE gels were excised from the silver gels (Fig. 2c, f), and were further analyzed by $\mathrm{LC} /$ MS-MS and BLASTp.

In total, 8 proteins were identified by incubating with the plasma of $7 \mathrm{dpi}$ mice. Analyzed with $B$. microti strain RI database by BLASTn, the 8 proteins were peptide alpha-N-acetyltransferase, hypothetical protein and 6 unnamed proteins (Additional file 2: Table S2). Seventy-nine B. microti proteins were confirmed by hybridizing $30 \mathrm{dpi}$ mice plasma, including 45 unnamed proteins, eleven hypothetical proteins, seven heat-shock protein 70s, four conserved and unknown function of Plasmodium proteins, and some other miscellaneous reported proteins (Additional file 2: Table S2).

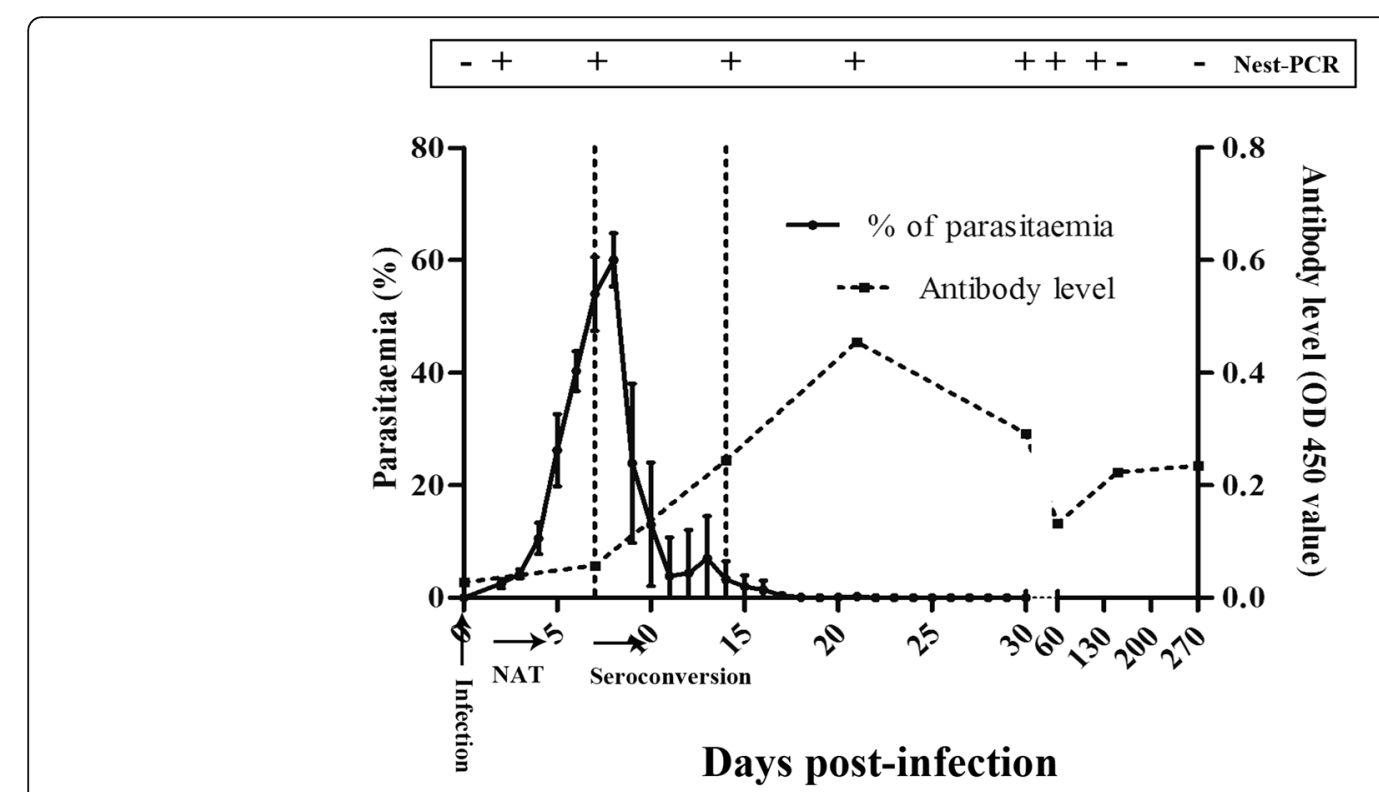

Fig. 1 Dynamics of parasitaemia, PCR analysis and antibody level in BALB/c mice with B. microti model. Each point represents the mean \pm SD 
Table 1 Compared sensitivity of Giemsa-stained thin blood smears and nested PCR for B. microti infection in BALB/C mice during 9 months (+, positive; -, negative)

\begin{tabular}{lll}
\hline dpi & $\begin{array}{l}\text { Microscopy (No. } \\
\text { positive/No. tested) }\end{array}$ & $\begin{array}{l}\text { Nested PCR (No. } \\
\text { positive/No. tested) }\end{array}$ \\
\hline 0 & $-(0 / 10)$ & $-(0 / 10)$ \\
3 & $+(10 / 10)$ & $+(10 / 10)$ \\
7 & $+(10 / 10)$ & $+(10 / 10)$ \\
14 & $+(10 / 10)$ & $+(10 / 10)$ \\
21 & $+(7 / 10)$ & $+(10 / 10)$ \\
30 & $+(2 / 10)$ & $+(10 / 10)$ \\
60 & $+(1 / 10)$ & $+(9 / 9)^{\mathrm{a}}$ \\
120 & $-(0 / 10)$ & $+(1 / 10)$ \\
$150^{\mathrm{b}}$ & $-(0 / 9)$ & $-(0 / 9)$ \\
$270^{c}$ & $-(0 / 6)$ & $-(0 / 6)$ \\
\hline
\end{tabular}

Abbreviation: dpi days post-infection

${ }^{a}$ One sample was unavailable for PCR detection

${ }^{\mathrm{b}}$ Nine mice alive on $150 \mathrm{dpi}$

'Six mice alive on $270 \mathrm{dpi}$

\section{PCR amplification of fragments and In-Fusion cloning}

From a total of $128 \mathrm{~B}$. microti gene fragments, 113 fragments were successfully amplified (88.3\%) (Table 2). The cloning results showed that 109 gene fragments were successfully cloned (96.4\%), including all the gene fragments identified by 7 dpi plasma samples (Table 2).

Of the 109 fragments, 87 (79.8\%) yielded protein products detected by western blot (Table 2, Fig. 3). However, few proteins migrated differently compared with the expected, as which has been reported for a variety of proteins expressed by the WGCF system [46].

\section{Acquiring immunoreactivity profiles}

The protein array with eighty-seven recombinant proteins were produced and probed with the pooled plasma of ten mice across ten different time points $(0,3,7,14,21,30,60$, 120, 150 and $270 \mathrm{dpi}$ ) to detect their immunoreactivity with IgG and IgM, respectively (Additional file 6: Figure S1). The different immunoreactivity profiles with IgG and IgM were presented as heatmaps Fig. 4a and b, respectively, for interpretation.

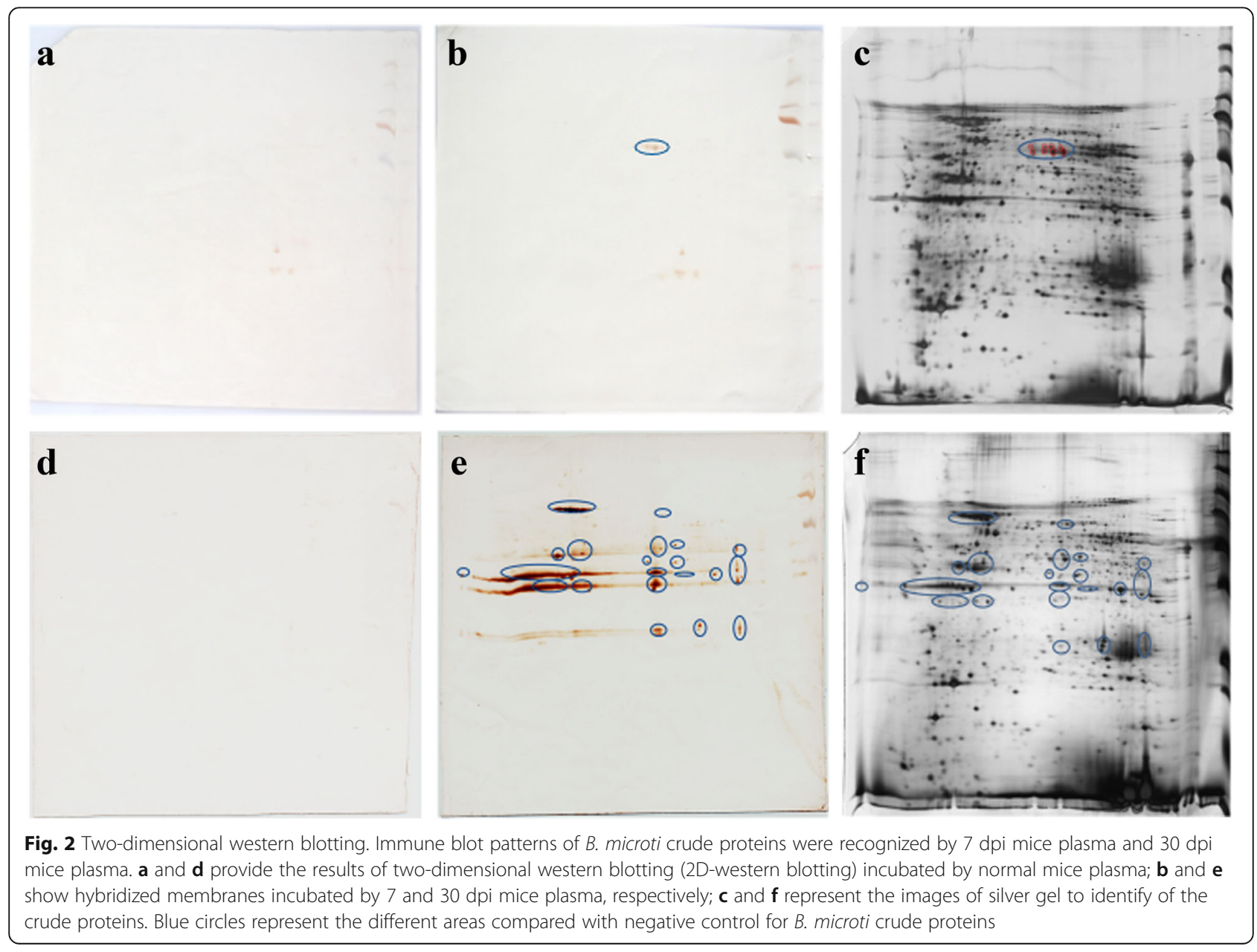


Table 2 High-throughput cloning and expression of B. microti gene fragments

\begin{tabular}{lllll}
\hline & $\begin{array}{l}\text { B. microti gene } \\
\text { fragments }\end{array}$ & $\begin{array}{l}\text { PCR } \\
\text { amplification (\%) }\end{array}$ & $\begin{array}{l}\text { In-fusion } \\
\text { cloning (\%) }\end{array}$ & $\begin{array}{l}\text { Expressed by } \\
\text { the WGCF (\%) }\end{array}$ \\
\hline $\begin{array}{l}\text { Bm2D- } \\
\text { 30 dpi }\end{array}$ & 119 & $104(87.4)$ & $100(96.2)$ & $80(80.0)$ \\
$\begin{array}{l}\text { Bm2D- } \\
7 \text { dpi }\end{array}$ & $9(100)$ & $9(100)$ & $7(77.8)$
\end{tabular}

Abbreviation: dpi days post-infection

Examining IgG antibody responses, it was shown that plasma from 0, 3, 7 and 270 dpi subjects showed low reactivity against all WGCF expressed proteins (Additional file 6: Figure S1A: a-c, j), whereas plasma from 14 to 150 dpi subjects showed clear reactivity (Additional file 6: Figure S1A: d-i). The heatmap shows four different patterns, Group 1 (11 antigens), Group 2 (47 antigens), Group 3 (29 antigens) and Group 4 (only one antigen, which was purified as a recombinant protein expressed in $E$. coli), were clustered showed in Fig. 4a and Additional file 7: Table S6.

Four patterns presented respectively very high, high, moderate and low immunoreactivity. According to their expression patterns, as described below, five antigens were selected for the further evaluation, including antigens 2D5 (AAO18095.1/ BMR1_02g04275-t32_1), 2D29
(CCF74204.1/ BMR1_03g00005-t32_1), 2D41 (CCF75408.1/ BmR1_04g06050-t32_1) and Bm7 (CCF73510.1) from Group 1, Group 2, Group 3 and Group 4 with high reaction from $14 \mathrm{dpi}$ to $270 \mathrm{dpi}$, as well as antigen 2D33 (CCF74637.1/ BMR1_03g02171-t32_1) from Group 3 with lower reactivity after 2 months. However, with IgM antibody responses, most proteins showed significant immunoreactivity to the plasma of 14 to 30 dpi (Additional file 6: Figure S1B: d-f), and lower reactivity before $7 \mathrm{dpi}$ and after $30 \mathrm{dpi}$ (Additional file 6: Figure S1B: a-c, g-j). Likewise, four different patterns, Group 1 (19 proteins), Group 2 (50 proteins), Group 3 (18 proteins) and Group 4 (one protein), were clustered showed in Fig. 4b and Additional file 7: Table S6. The first three groups did not present significant differences, only one antigen, 2D97 (CCF75281.1/BmR1_04g05415-t32_1) from Group 3, showed IgM immunoreactivity during 3 dpi and 7 dpi (Fig. 4b, Additional file 6: Figure S1), which may be a possible candidate for early detection. These proteins are also expected as B. microti vaccine candidates and diagnosed antigens.

\section{Evaluation of recombinant proteins as diagnostic and vaccine antigens}

rBm2D33 and rBm2D41 were expressed in Escherichia coli as soluble proteins and $\mathrm{rBm} 2 \mathrm{D} 97$ and $\mathrm{rBm} 7$ were

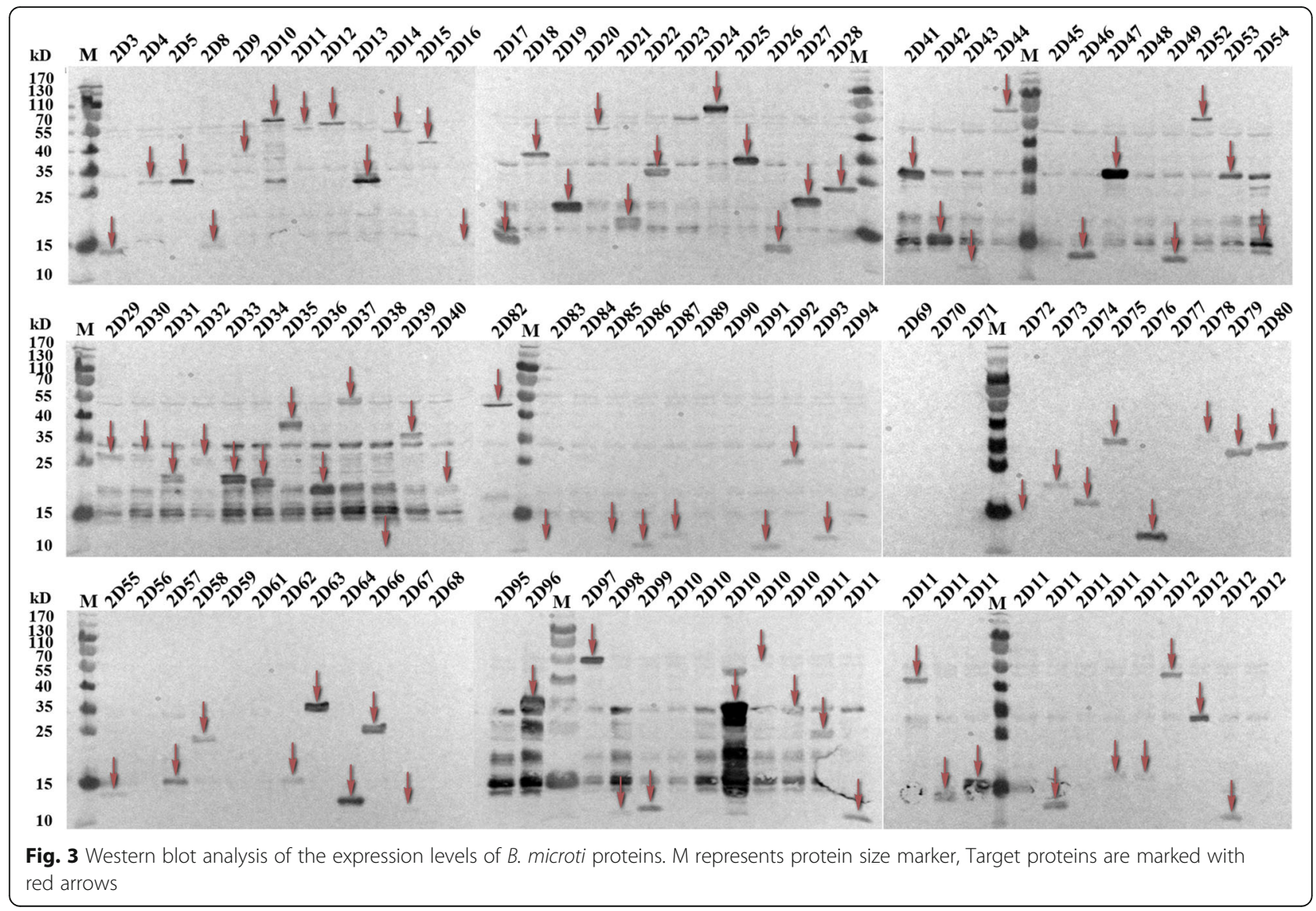




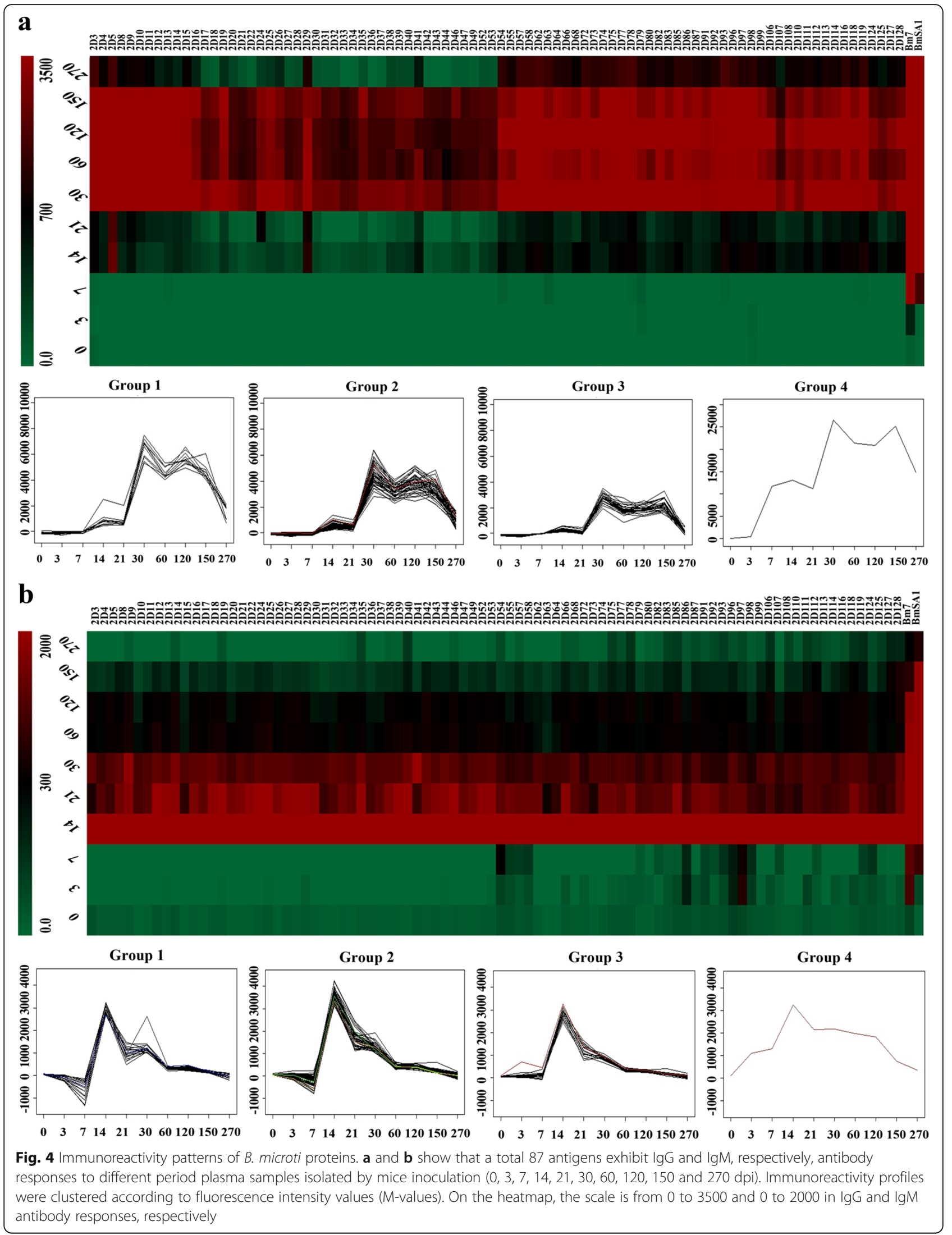


produced as inclusion bodies (Additional file 8: Figure S2) with the molecular weights of $42 \mathrm{KDa}, 39 \mathrm{KDa}, 38 \mathrm{KDa}$ and $24 \mathrm{KDa}$, respectively.

The immunoreactivity between the purified antigens and the different time periods of plasma samples from mice inoculated $B$. microti $(0,3,7,14,21,30,60,120$, 150 and $270 \mathrm{dpi}$ ) showed similar trends when compared with heatmap analysis of protein arrays (Figs. 4, 5). rBm2D33 and rBm2D41 showed better characterization of $B$. microti diagnostic protein in ELISA reactivity, which $62.5 \%$ (5 of 8 tested samples) and 50\% (4 of 8 tested samples), respectively, compared to rBmSA1 with no obvious detection (Fig. 6a). The reactivity between the patients' plasma and the multi-antigens combined with rBm2D33, $\mathrm{rBm} 2 \mathrm{D} 41$ and $\mathrm{rBm} 7$, showed similar sensitivity to $\mathrm{rBm} 2 \mathrm{D} 33$, which show $62.5 \%$ of samples testing positive (Fig. 6a).

Furthermore, the specificity of the diagnostic protein markers was evaluated by cross-reactivity to known Plasmodium infections. The reaction with 10 vivax malaria plasma samples showed there were $1(10 \%), 2(20 \%)$, 3 (30\%), 4 (40\%) and 7 (70\%) diagnosed as being positive by $\mathrm{rBm} 7, \mathrm{rBmSA} 1, \mathrm{rBm} 2 \mathrm{D} 33, \mathrm{rBm} 2 \mathrm{D} 41$ and rBm2D97, respectively (Fig. 6b). Furthermore, the reaction with 10 falciparum malaria plasma samples, showed no samples diagnosed as being positive by $\mathrm{rBm} 7$ and $\mathrm{rBm} 2 \mathrm{D} 33$, and 2 (20\%) by rBm2D41and rBmSA1, and $4(40 \%)$ by rBm2D97 diagnosed as being positive (Fig. $6 \mathrm{~b}$ ). Therefore, the sensitivity and cross-reactivity to Plasmodium of rBm2D33 was better than other antigens.

Two hundred febrile cases from a malaria endemic area (Tengchong, Yunnan Province) were used to evaluate the infection state of $B$. microti, P. falciparum and $P$. vivax. The PCR detection method results showed that there were ten positive cases of $B$. microti, 14 and 4 were positive cases of $P$. vivax and $P$. falciparum, respectively, including one co-infection case of $P$. vivax and $P$. falciparum, but no co-infection of Plasmodium or B. microti case was found. These 200 plasma samples were analyzed by ELISA using all selected B. microti antigens (Additional file 9: Figure S3), and samples identified as positive are displayed in Table 3. Finally, the results of evaluating febrile cases are displayed in heatmap including nested-PCR and recombinant proteins by ELISA (Additional file 10: Figure S4). Of the 200 febrile cases examined, 32 and 34 were detected as being positive by $\mathrm{rBm} 2 \mathrm{D} 41$ and $\mathrm{rBm} 7$ which included 1and 2 PCR positive cases of $B$. microti and 7 PCR positive cases of Plasmodium, respectively. Thirty-two were detected as being positive by rBm2D33 which included 2 PCR-positive cases of B. microti and 9 PCR-positive cases of Plasmodium. Twenty-seven were detected as being positive by rBm2D97 which included 1 PCR positive case of B. microti and 10 PCR-positive cases of Plasmodium. rBmSA1 and crude B. microti proteins were used as controls. Thirty-eight and fifty-eight were detected as being positive, including 1 and 3 PCR-positive cases of B. microti and 14 and 9 PCR-positive cases of Plasmodium. Thus, more antibody-positive and PCR-negative cases were present in the examined cohort.

\section{Vaccination and challenge infection}

The antigens with high immunoreactivity were considered to be of great potential for use in a vaccine. Based on the preliminary screening and further immunoreaction

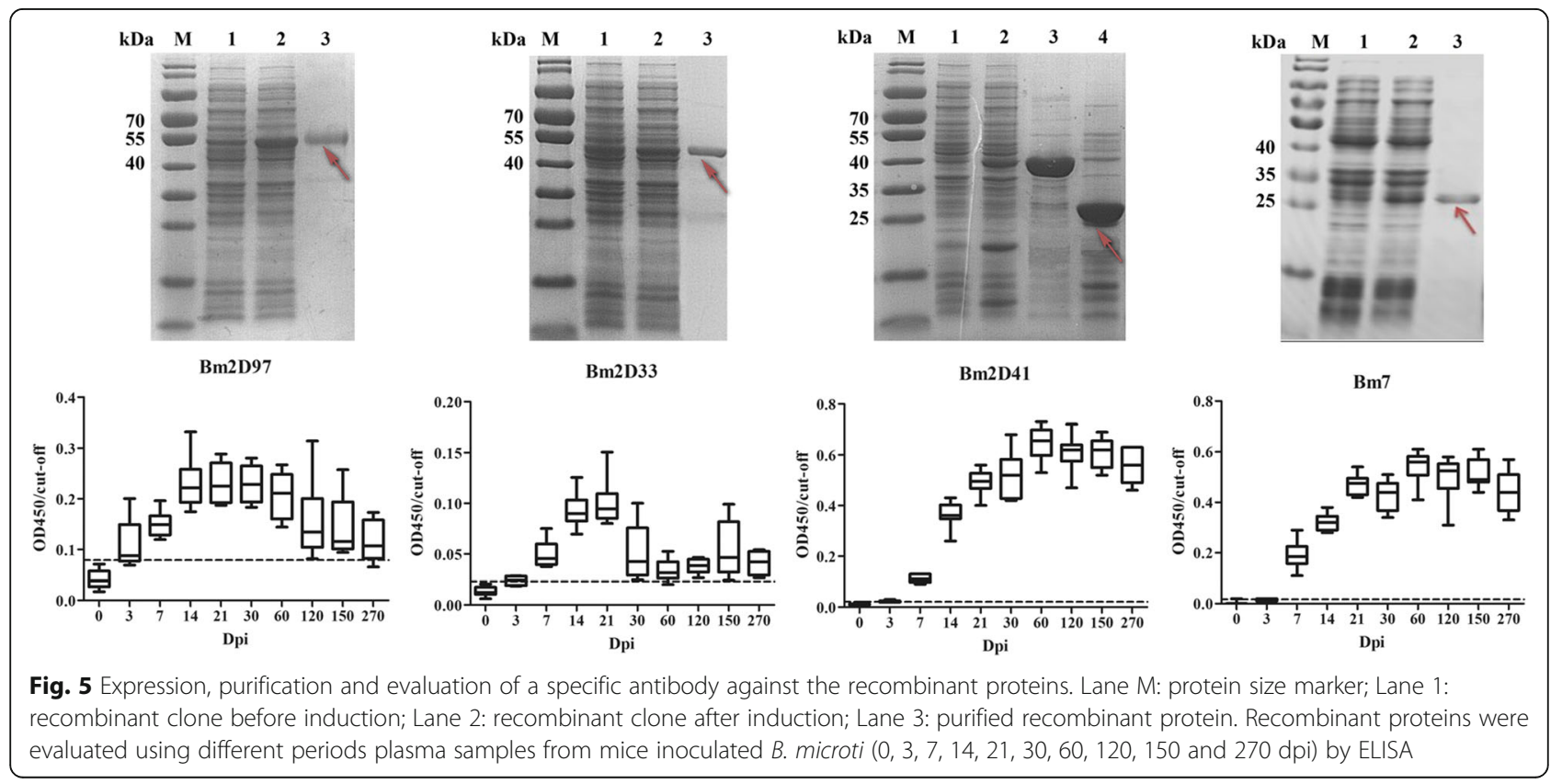



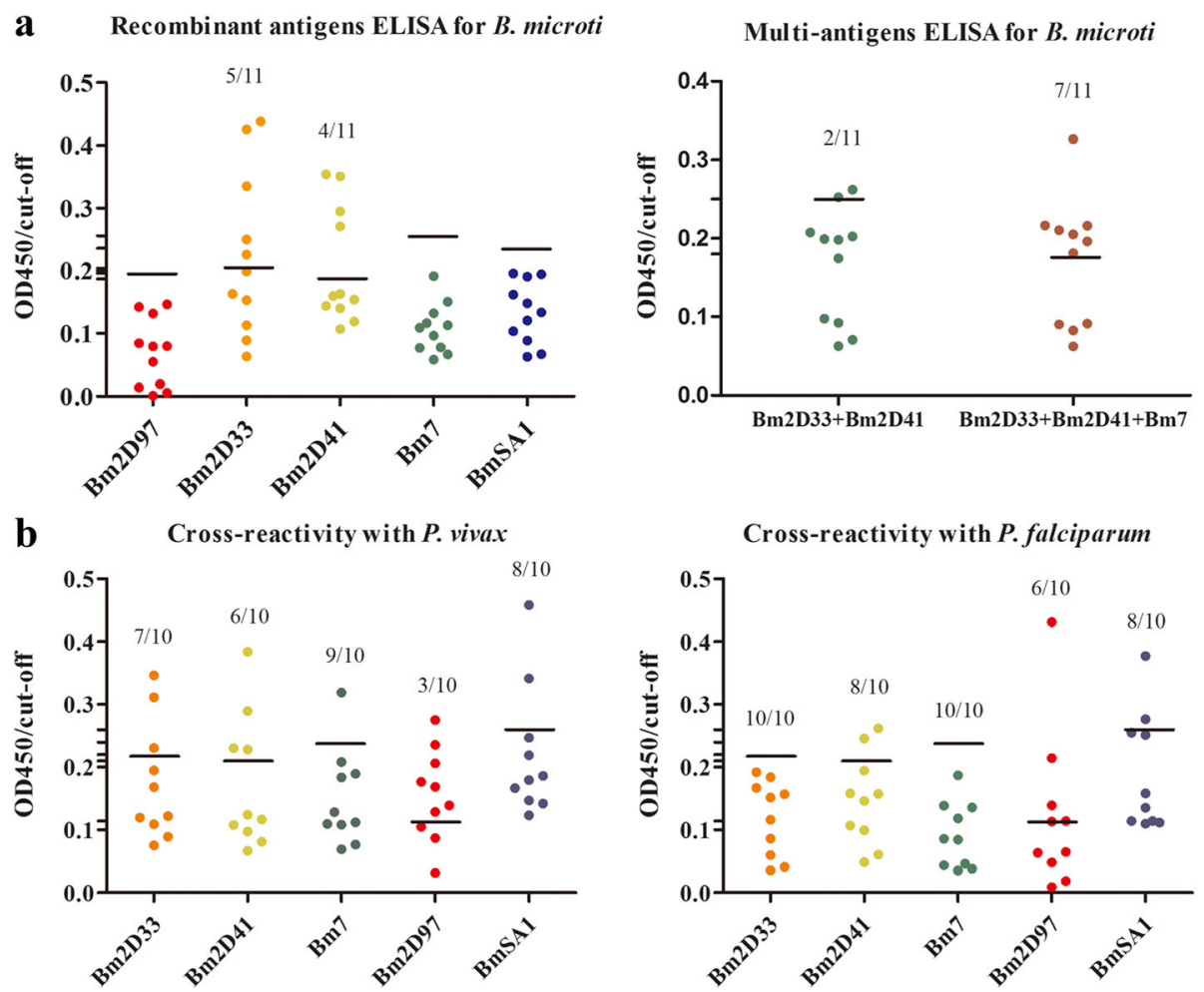

Fig. 6 Comparison of the sensitivity and specificity of B. microti recombinant antigens. a ELISA reactivity of $B$. microti recombinant antigens and multi-antigens to babesiosis patient plasma $(n=8)$. $\mathbf{b}$ ELISA reactivity of $B$. microti recombinant antigens to $P$. vivax and $P$. falciparum patient plasma $(n=10)$

evaluation results, we found $\mathrm{rBm} 7$ and $\mathrm{rBm} 2 \mathrm{D} 41$ could induce higher antibody expression. Thus, the parasitaemia and antibody levels of mice immunized with Bm2D41 and $\mathrm{Bm} 7$ mice were evaluated. After the 3rd booster for the immunizations, the specific antibody levels in mice plasma had significantly increased $\left(t_{(4)}=15.64, P=2.9 \times 10^{-7}\right.$ and $t_{(4)}=13.90, P=6.5 \times 10^{-7}$, respectively) (Fig. 7a) and all mice were challenged with $1 \times 10^{7} \mathrm{~B}$. microti-infected erythrocytes. In the Bm2D41-immunized group, the parasitaemia were clearly lower than those of the control mice that received either PBS or no immunization during from days 7-21 $\left(F_{(2,7)}=4.79-4.78, P=0.0031-0.049\right)$, except for Day $13\left(F_{(2,7)}=2.255, P=0.1755\right)$ (Fig. 7b). Peak parasitaemia appeared at 7 days after the challenge infection and reached an average of $25.4 \%$ and $23.0 \%$ in the control group of immunization with PBS-immunized and that of no immunization group, respectively. However, compared with control group, the Bm2D-41 immunized group showed the lower parasitaemia peak of $15.9 \%$, while the parasitaemia of the Bm7 immunized group did not decline significantly. Freund's adjuvant itself could affect the host and cause a certain inhibition of parasitaemia. Parasites had not been completely eliminated by day 30 post-challenge in all groups tested. After the final booster immunization, the antibody titers were maintained at a high level up to the chronic stage of infection in both candidate vaccines (Fig. 7).

\section{Discussion}

Different clinical presentations have been reported in babesiosis, including asymptomatic infection, malaria-like complications or even death [47]. Due to its broad clinical spectrum, misdiagnoses and missed diagnoses are often encountered. Currently, babesiosis is identified by a direct-smear evaluation, antibody tests, PCR assays and

Table 3 Samples positive for B. microti in febrile cases

\begin{tabular}{|c|c|c|c|c|c|c|c|}
\hline \multicolumn{2}{|c|}{ Detection method } & \multicolumn{6}{|c|}{ Recombinant proteins as diagnostic antigens } \\
\hline PCR & ELISA & Crude protein & rBmSA1 & $\mathrm{rBm} 2 \mathrm{D} 41$ & $\mathrm{rBm} 7$ & $\mathrm{rBm} 2 \mathrm{D} 97$ & rBm2D33 \\
\hline+ & - & 7 & 9 & 9 & 8 & 9 & 8 \\
\hline+ & + & 3 & 1 & 1 & 2 & 1 & 2 \\
\hline- & + & 55 & 37 & 31 & 32 & 26 & 30 \\
\hline
\end{tabular}



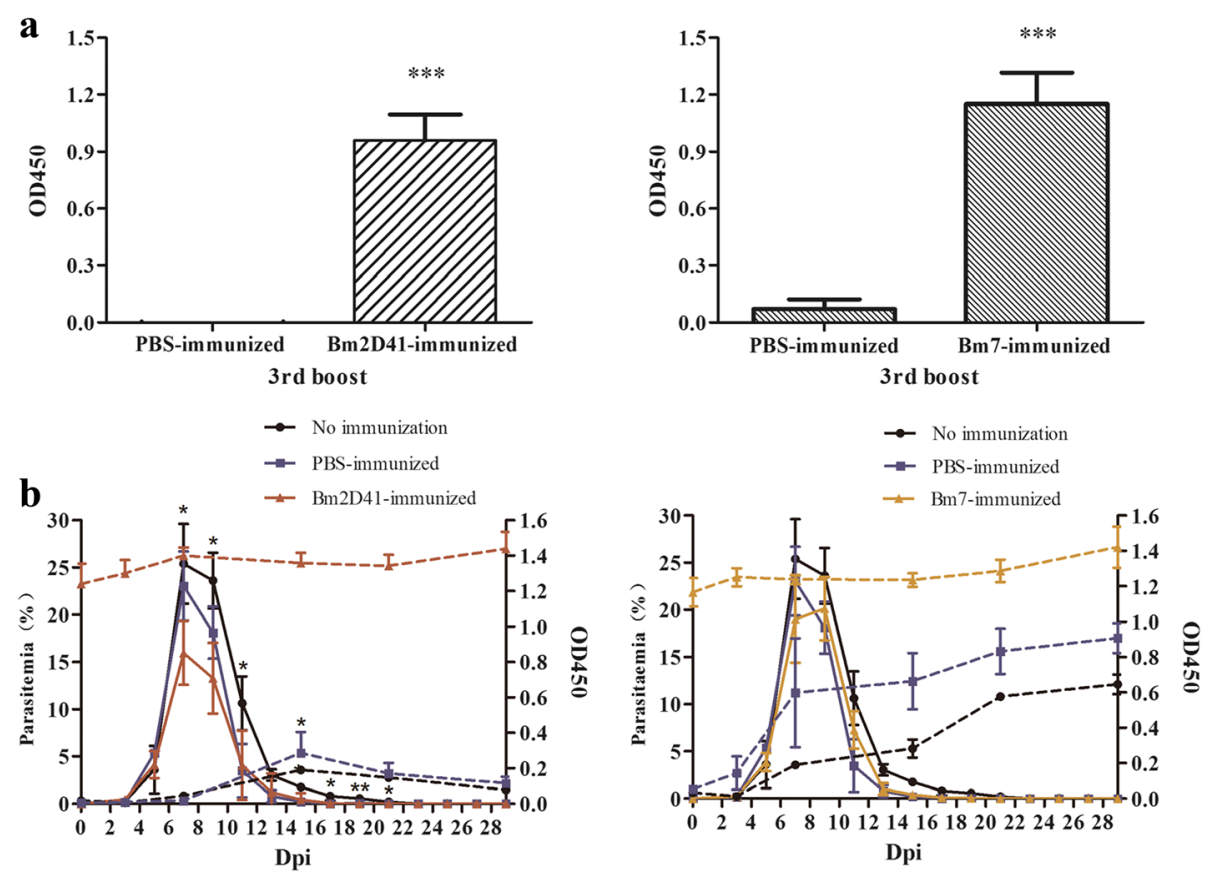

Fig. 7 The evaluation and effect of immunization with Bm2D41 and Bm7. a The levels of IgG immunized with Bm2D41 and Bm7 in BALB/C mice. b The parasitaemia and antibody levels of BABL/C mice after challenge infection with B. microti. Asterisks indicate statistically significant differences $\left[{ }^{*} P<0.05,{ }^{*} P<0.005,{ }^{* *} P<0.0001\right.$ (compared to either the PBS-immunized or non-immunized BABL/c mice)]. The solid and dashed lines denote parasitaemia and antibody titter, respectively

animal sub-inoculation [7, 48]. Microscopic examination with a Giemsa-stained blood smear was considered to be the gold-standard for a babesiosis diagnosis. However, it is difficult to discriminate B. microti in blood smears, because of low parasitaemia levels and their morphological similarity to Plasmodium spp., which may result in inaccurate diagnosis. Comparatively, PCR diagnosis methods while more sensitive and specific, are still not accurate enough for the diagnosis of low parasitaemias or samples during window infection periods. Antibody diagnosis was highly sensitive and suitable for low parasitaemias detection. However, it was still not effective in detecting the infection during the window period for antibody detection. Furthermore, false positives are often eventually identified later in situations where the antibody is present even after the clearance of B. microti [7, 47-49].

In this study, the percentage of parasitized erythrocytes, nucleic acid and antibody levels, as well as their correlation were analyzed in the BABL/c mouse model. The results indicate that the percentage of parasitized erythrocytes reached the peak after one week post-inoculation, and markedly reduced until the clearance of the parasite. The detected percentages of parasitized erythrocytes in this study was consistent with previously reported investigations, both in animal models and in the clinic $[9,14,17,19]$. The window period for antibody analysis is 0 to $7 \mathrm{dpi}$. With the gradual reduction of the parasitaemia percentage, IgG increased and reached a peak after 30 days, and the high IgG level could be maintained for 9 months. These results indicate that antibody levels could be used as an indicator of B. microti infection. In addition, our results show that the specific IgG played important roles in the immune protection in babesiosis.

The current study also showed that PCR analysis was more sensitive than blood smear evaluations and could be complementary to antibody diagnosis during the window period of the infection. However, it was clear that the period for PCR detection was relatively short. A study reporting blood screening in the USA showed that a portion of blood donors could remain antibody-positive for more than one year. Compared to the PCR results, donors with high level of antibodies were more likely to be active or recently infected with $B$. microti than PCR-negative donors with low-titer antibodies $[16,18]$. Thus, the antibody diagnosis result was an important parameter for assessment of $B$. microti infection, which was especially effective in diagnosing asymptomatic infections.

In previous research focusing on immune protection mechanisms, IgM was shown as an early response to the B. microti infection. Also, IgM levels gradually reached a peak with the increased level of parasitaemia while specific IgG response increased along with the decline of parasitaemia. When IgG reached the peak, parasites were cleared or were present in much lower levels [14]. 
In our study, the $B$. microti crude antigenic proteins were screened by the plasma collected from the peak of parasitaemia and antibody levels. We compared 87 2D-western positive proteins with the top twenty reactive proteins showed in publication of Silva et al. [22] and 19 B. microti GPI proteins showed in publication of Cornillot et al. [21] and found two proteins that were identified in the first comparison, which are 2D5 (AAO18095.1/BMR1_02g04275-t32_1) and 2D13 (CCF73151.1/BMR1_01G03465-t32_1). However, none was hit within $19 \mathrm{~B}$. microti GPI proteins. We consider the possible reasons maybe related with the different strains and time points used for plasma screening reactive antigen candidates. Furthermore, we also payed attention to BmSA1, which is one of the most expressed proteins, yet was missed in this preliminary screening. However, it was shown that several of the highly antigenic proteins are the most expressed ones [22]. This result indicated that the 2D-western screening may have missed some proteins when they matched the positive reaction protein based on their position on the two gels. Therefore, we combined the 2D-western and bioinformatics analysis for the preliminary screening. The protein microarray results presented in the heatmap analysis showed the trends of immune reaction detected with recombinant antigens during the different periods of infected $\mathrm{BALB} / \mathrm{c}$ mice. This showed similar dynamics to that of antibody levels tested by crude B. microti proteins. Several antigens presented high immune reactions, including 2D5, 2D29 (truncated expressed 2D5), 2D41 and Bm7. These antigens could be the potential diagnostic biomarkers for B. microti infection. It was noteworthy that in the animal models, low levels of parasitized erythrocytes or even the apparent absence of parasites, could still present a challenge or secondary infection of B. microti, which may differ to the first initial infection [15, 17]. Thus, the antigens with high immune reactions could be of great potential as targets in a vaccine and aid in asymptomatic infection detection. Several antigens with low immunoreactivity as the parasites disappeared or were cleared were detected in the investigation of the antigen spectra, such as 2D33 and 2D36. These antigens could be used as potential biomarkers for the acute period of infection. Low responses were observed when investigating the immunoreactivity profiles of IgM. In accordance with levels of IgM antibody and parasitaemia, the reaction trends of 2D97 showed an early response to parasite infection, thus indicating its potential as a biomarker for early diagnosis of babesiosis.

As discussed above, hosts with positive antibody reactions could still present asymptomatically, but be infected, and thus should be carefully observed. Biomarker antigens with desirable properties with the necessary characterization have been identified in our study and we anticipate could be used developed to screen $B$. microti infections in the future. Although high efficiency in detection of infection in mice were shown, our antigens showed low efficiency with diagnosed patients or infected individuals. This was possibly because of the variance of infection stage and immune response in different hosts [47]. Compared to the reported diagnostic antigen rBMSA1, the rBm2D33 and the combination of $\mathrm{rBm} 2 \mathrm{D} 33, \mathrm{rBm} 2 \mathrm{D} 41$ and $\mathrm{rBm} 7$ showed higher sensitivities.

Babesiosis and malaria are similar in symptoms and immune mechanisms, especially when observing the morphology; the $P$. falciparum also has a ring shape in the erythrocyte, which resembled $B$. microti, making it difficult to distinguish $[47,50,51]$. Occasionally, a co-infection of $B$. microti and Plasmodium parasites is reported [38], leading to misdiagnoses and missed diagnoses. In this regard, a diagnostic antigen is expected to distinguish the Plasmodium and $B$. microti infection effectively. In this study, the diagnostic candidate antigens showed low cross-reaction with $P$. falciparum infections compared with $P$. vivax infections, thus the candidate antigens exhibited advantages in distinguishing these two parasites during the infection stage.

Babesiosis is transmitted through infected blood or blood related products, which severely threatens public health [48]. According to a recent report, $97.3 \%$ of the positive blood-donation samples tested in the USA were antibody positive, among which $80 \%$ were PCR negative. Meanwhile, evidence already indicates the risks in blood transmission, even in the PCR negative samples [18]. In regards to the recent babesiosis cases reported in China [38, 52, 53], two hundred microscopically negative samples of blood cells and plasma were collected in a malaria epidemic area in Tengchong, Yunnan Province, for further tests and screening in our study. The detection of these samples was carried out using the potential antigen biomarkers obtained in this study, crude $B$. microti proteins and PCR, respectively. As a result, the positive rates were $13.5-19.0 \%, 27.5 \%$ and $5 \%$, respectively. PCR negative rates were $72.0-78.0 \%$ for potential biomarker antigen positive samples, and $84.6 \%$ for crude B. microti protein positive samples. The results further highlighted the risks of babesiosis spreading due to the missed diagnoses using only PCR methods.

The potential of the obtained antigens as a possible vaccine was also evaluated in our study. In the immune protection experiment, $\mathrm{rBm} 2 \mathrm{D} 41$ reduced the peak value by $37.4 \%$, thus provided an effective protection to the $B$. microti infection, and also prevented serious hemolysis symptoms. The preliminary tests indicated that the potential antigen biomarker also possessed a potential vaccine property, thus our team is encouraged to produce more investigations with biomarker proteins to be screened and 
discovered. Also, whether the risk of infection by blood transfusion or tick bite could be lowered by the vaccination was also worth investigating.

\section{Conclusions}

The diagnosis technologies for babesiosis, including microscopic examination, PCR assays and antibody tests represent the infection at different stages. This study especially pinpointed the importance of antibody detection. The screened biomarkers for the disease progression during babesiosis infection in this work, provides useful information for the diagnosis and vaccine development for this serious risk in public health.

\section{Additional files}

Additional file 1: Table S1. The samples information of patients with babesiosis. (DOCX $14 \mathrm{~kb}$ )

Additional file 2: Table S2. Identities of B. microti crude antigenic proteins recognized by $7 \mathrm{dpi}$ and $30 \mathrm{dpi}$ plasma samples. (DOCX $25 \mathrm{~kb}$ )

Additional file 3: Table S3. The sequence information of $B$. microti gene fragments and primers of in-fusion clone. (DOCX $51 \mathrm{~kb}$ )

Additional file 4: Table S4. The primer sequences of $B$. microti genes in prokaryotic cloning and expression. (DOCX $14 \mathrm{~kb}$ )

Additional file 5: Table S5. The primer sequences of $P$. vivax and $P$. falciparum. (DOCX $14 \mathrm{~kb}$ )

Additional file 6: Figure S1. Antibody profiling of $B$. microti proteins by protein arrays. Crude $B$. microti proteins (2D3-2D54, 2D55-2D128) react with plasma samples across ten different time points (a-j: 0, 3, 7, 14, 21 , $30,60,120,150$ and $270 \mathrm{dpi}$ ). The reactions were detected with antimouse $\lg G(A)$ and anti-mouse lgM (B). Control reactions of wheat germ lysate that lacked vector templates (white box) and reactions of purified recombinant proteins (red box) served as negative and positive controls. Well characterized reactions with target proteins are marked with orange boxes. (TIF $3404 \mathrm{~kb}$ )

Additional file 7: Table S6. Babesia microti proteins were grouped by immunoreactivity patterns. (DOCX $17 \mathrm{~kb}$ )

Additional file 8: Figure S2. Soluble expression analysis of rBm2D97, rBm2D33, rBm2D41 and rBm7. M: MW markers; Lane 1: pre-induction extraction of whole-cell protein; Lane 2: pre-induction supernatant; Lane 3: pre-induction precipitation; Lane 4: extraction of whole-cell proteinpost IPTG induction; Lane 5: supernatant post IPTG induction; Lane 6: precipitation post IPTG induction. Target proteins are marked with red arrow. (TIFF $1265 \mathrm{~kb}$ )

Additional file 9: Figure S3. Two hundred febrile cases evaluated by crude B.microti proteins and recombinant antigens. (TIFF $417 \mathrm{~kb}$ )

Additional file 10: Figure S4. Evaluating febrile cases using nested-PCR and recombinant proteins by ELISA. (TIF $6386 \mathrm{~kb}$ )

\footnotetext{
Abbreviations

2-DE: Two-dimensional electrophoresis; ANOVA: One-way analysis of variance; CAMS: Chinese Academy of Medical Sciences; China CDC: Chinese Center for Disease Control and Prevention; DAB: 3, 3'-Diaminobenzidine; dpi: Days post-infection; ELISA: Enzyme-linked immunosorbent assay; FDA: Food and Drug Administration; GPI: Glycosyl-phosphatidyl inositol; HCA: Hierarchical clustering analysis; IgG: Immunoglobulin G; IgM: Immunoglobulin M; LC/ MS: Liquid chromatography-mass spectrometry; MeV: Multi-array experiment viewer; NIPD: National Institute of Parasitic Diseases; OD: Optical density; PCR: Polymerase-chain-reaction; PVDF: Polyvinylidene fluoride; SD: Standard deviation; SDS-PAGE: Sodium dodecyl sulfate polyacrylamide gel electrophoresis; TTB: Transfusion-transmitted babesiosis; WGCF: Wheat germ cell-free
}

\section{Acknowledgments}

We would like to thank Professors Ji-Ming Zhang from Huashan Sub-Hospital of Fudan University, Guo-Qing Zang from Shanghai Sixth Hospital, Juan Du from Shanghai Changzheng Hospital for providing the samples. We especially want to thank Dr. Geoffery Gobert from Queen's University Belfast and Dr. Dave Dyer from University of Wisconsin-Madison for critical reading and review of this manuscript.

\section{Funding}

This work was supported by the Fourth Round of a Three-Year Public Health Action Plan (2015-2017) in Shanghai (Grant No. GWIV-29), Strengthen Action Plan for Shanghai Public Health System Construction 2011-2013 (Grant No. GW-11), National S and T Major Program (Grant No. 2009ZX10004-302), Chinese Special Program for Scientific Research of Public Health (Grant No. 201502021, 201202019), and International Science and Technology Cooperation Program of China (Grant No. 2014DFA31130).The funders had no role in study design, data collection and analysis, decision to publish or preparation of the manuscript.

\section{Availability of data and materials}

The datasets generated and/or analyzed during the current study are available in the ProteomeXchange Consortium repository with the data set identifier IPX0001196000. The other data generated or analyzed during this study are included in this published article and its additional files.

\section{Authors' contributions}

Conceived and designed the experiments: BX, XFL and WH. Performed the experiments: BX, XFL, YCC, JLH, RXZ, JL, QFW and CSS. Analyzed the data: BX, $X F L, J X C$ and $\mathrm{WH}$. Contributed reagents/materials/analysis tools: $B X, X F L, Y C C$, $J H C, X J C, X Z, T Z, S B C, X N X, Y Z$ and YFF. Wrote the paper: BX, XFL, RXZ, XNZ and $\mathrm{WH}$. All authors read and approved the final manuscript.

\section{Ethics approval and consent to participate}

Ethical clearance for the collection and detection of human samples was obtained from the Ethics Committee of the National Institute of Parasitic Diseases (NIPD), Chinese Center for Disease Control and Prevention (China CDC). The objectives, procedures and potential risks were verbally explained to all participants. Signed written informed consent was obtained from all study participants. All participants were adults in this study. Animals were handled in accordance with good animal practice strictly according to the Animal Ethics Procedures and Guidelines of the People's Republic of China. The protocol for sampling from animals had been approved by the Anima Welfare\& Ethics Committee of the National Institute of Parasitic Diseases, Chinese Center for Disease Control and Prevention in Shanghai (Permit No: IPD-2012-5)

\section{Consent for publication}

We have obtained consent to publish from the participants (or legal parents or guardians for children) to report individual patient data.

\section{Competing interests}

The authors declare that they have no competing interests.

\section{Publisher's Note}

Springer Nature remains neutral with regard to jurisdictional claims in published maps and institutional affiliations.

\section{Author details}

${ }^{1}$ National Institute of Parasitic Diseases, Chinese Center for Disease Control and Prevention, WHO Collaborating Center for Tropical Diseases; National Center for International Research on Tropical Diseases, Ministry of Science and Technology; Key Laboratory of Parasite and Vector Biology, National Health and Family Planning Commission, Shanghai, People's Republic of China. ${ }^{2}$ Department of Microbiology and Microbial Engineering, School of Life Sciences, Fudan University, Shanghai, People's Republic of China. ${ }^{3}$ Institute of Biomedical Sciences, Department of Medical Microbiology and Parasitology, School of Basic Medical Sciences, Fudan University, Shanghai, People's Republic of China. ${ }^{4}$ Department of Parasitology, Medical College of Soochow University, Suzhou, People's Republic of China. 


\section{Received: 8 February 2018 Accepted: 13 June 2018}

\section{Published online: 03 July 2018}

\section{References}

1. Esernio-Jenssen D, Scimeca PG, Benach JL, Tenenbaum MJ. Transplacental/ perinatal babesiosis. J Pediatr. 1987;1 10:570-2.

2. Fox LAM, Wingerter S, Ahmed A, Arnold A, Chou J, Rhein L, et al. Neonatal babesiosis - case report and review of the literature. Pediatr Infect Dis J. 2006:25:169-73.

3. Gubernot DM, Nakhasi HP. Transfusion-transmitted babesiosis in the United States: summary of a workshop. Transfusion. 2009:49:2759-71.

4. Levine ND. The protozoan phylum Apicomplexa. Volumes I and II. Boca Raton: CRC Press; 1988.

5. Spielman A, Wilson ML, Levine JF, Piesman J. Ecology of /xodes dammini-borne human babesiosis and Lyme disease. Annu Rev Entomol. 1985:30:439-60.

6. Vannier E, Krause PJ. Human babesiosis. N Engl J Med. 2012;366:2397-407.

7. Vannier EG, Diuk-Wasser MA, Ben Mamoun C, Krause PJ. Babesiosis. Infect Dis Clin North Am. 2015;29:357-69.

8. Herwaldt BL, Linden JV, Bosserman E, Young C, Olkowska D, Wilson M. Transfusion-associated babesiosis in the United States: a description of cases. Ann Intern Med. 2011;155:509-19.

9. Gumber S, Nascimento FS, Rogers KA, Bishop HS, Rivera HN, Xayavong MV, et al. Experimental transfusion-induced Babesia microti infection: dynamics of parasitemia and immune responses in a rhesus macaque model. Transfusion. 2016;56:1508-19.

10. Ruebush TK, Juranek DD, Chisholm ES, Snow PC, Healy GR, Sulzer AJ. Human babesiosis on Nantucket Island evidence for self-limited and subclinical infections. N Engl J Med. 1977;297:825-7.

11. Hunfeld KP, Hildebrandt A, Gray JS. Babesiosis: recent insights into an ancient disease. Int J Parasit. 2008:38:1219-37.

12. Krause PJ, Gewurz BE, Hill D, Marty FM, Vannier E, Foppa IM, et al. Persistent and relapsing babesiosis in immunocompromised patients. Clin Infect Dis. 2008:46:370-6.

13. Falagas ME, Klempner MS. Babesiosis in patients with AIDS: a chronic infection presenting as fever of unknown origin. Clin Infect Dis. 1996;22:809-12.

14. Ruebush TK. Human babesiosis in North America. Trans Roy Soc Trop Med Hyg. 1980;74:149-52.

15. Ruebush TK, Collins WE, Warren M. Experimental Babesia microti infections in Macaca mulatta recurrent parasitemia before and after splenectomy. Am J Trop Med Hyg. 1981;30:304-7.

16. Pastusiak K, Konopka E, Doligalska M, Sinski E. Babesia microti: parasitaemia and antibody responses to primary and challenge infections in BALB/C mice. Folia Parasitol. 2003:50:237-9.

17. Chen DH, Copeman DB, Burnell J, Hutchinson GW. Helper T cell and antibody responses to infection of CBA mice with Babesia microti. Parasite Immunol. 2000;22:81-8.

18. Moritz ED, Winton CS, Johnson ST, Krysztof DE, Townsend RL, Foster GA et al. Investigational screening for Babesia microti in a large repository of blood donor samples from nonendemic and endemic areas of the United States. Transfusion. 2014;54:2226-36.

19. Moritz ED, Winton CS, Tonnetti L, Townsend RL, Berardi VP, Hewins ME, et al. Screening for Babesia microti in the US blood supply. N Engl J Med. 2016:375:2236-45.

20. Hu RJ, Yeh MT, Hyland KE, Mather TN. Experimental Babesia microti infection in golden hamsters: immunoglobulin $\mathrm{G}$ response and recovery from severe hemolytic anemia. J Parasitol. 1996;82:728-32.

21. Cornillot E, Dassouli A, Pachikara N, Lawres L, Renard I, Francois C, et al. A targeted immunomic approach identifies diagnostic antigens in the human pathogen Babesia microti. Transfusion. 2016;56:2085-99.

22. Silva JC, Cornillot E, Mccracken C, Usmanibrown S, Dwivedi A, Ifeonu OO, et al. Genome-wide diversity and gene expression profiling of Babesia microti isolates identify polymorphic genes that mediate host-pathogen interactions. Sci Rep. 2016;6:35284.

23. Welc-Faleciak R, Bajer A, Bednarska M, Paziewska A, Sinski E. Long term monitoring of Babesia microti infection in BALB/C mice using nested PCR. Ann Agr Env Med. 2007;14:287-90.

24. Machado RZ, Valadao CAA, Melo WR, Alessi AC. Isolation of Babesia bigemina and Babesia bovis merozoites by ammonium-chloride lysis of infected erythrocytes. Brazilian J Med Biol Res. 1994;27:2591-8.

25. Ju C, Xu B, Lu Y, Mo XJ, Zhang T, Chen SB, et al. Comparative immunomic analysis of Schistosoma japonicum soluble egg antigens reacting with patient sera before and after praziquantel treatment. J Anim Vet Adv. 2012;11:2828-38.
26. Meitei NS, Apte A, Snovida SI, Rogers JC, Saba J. Automating mass spectrometry-based quantitative glycomics using aminoxy tandem mass tag reagents with SimGlycan. J Proteomics. 2015;127:211-22.

27. Vizcaino JA, Deutsch EW, Wang R, Csordas A, Reisinger F, Rios D, et al. ProteomeXchange provides globally coordinated proteomics data submission and dissemination. Nat Biotechnol. 2014;32:223-6.

28. Vizcaino JA, Cote RG, Csordas A, Dianes JA, Fabregat A, Foster JM, et al. The PRoteomics IDEntifications (PRIDE) database and associated tools: status in 2013. Nucleic Acids Res. 2013:41:1063-9.

29. Berrow NS, Alderton D, Owens RJ. The precise engineering of expression vectors using high-throughput in-fusion PCR cloning. Methods Mol Biol. 2009:498:75-90.

30. Petersen TN, Brunak S, Von HG, Nielsen H. SignalP 4.0: discriminating signal peptides from transmembrane regions. Nat Methods. 2011;8:785-6.

31. Eisenhaber B, Bork P, Eisenhaber F. Prediction of potential GPI-modification sites in proprotein sequences. J Mol Biol. 1999;292:741-58.

32. Pierleoni A, Martelli PL, Casadio R. PredGPI: a GPl-anchor predictor. BMC Bioinformatics. 2008:9:392.

33. Chen JH, Jung JW, Wang Y, Ha KS, Lu F, Lim CS, et al. Immunoproteomics profiling of blood stage Plasmodium vivax infection by high-throughput screening assays. J Proteome Res. 2010;9:6479-89.

34. Tsuboi T, Takeo S, Iriko H, Jin L, Tsuchimochi M, Matsuda S, et al. Wheat germ cell-free system-based production of malaria proteins for discovery of novel vaccine candidates. Infect Immun. 2008;76:1702-8.

35. Sun Jia-hui X, Bin J, Chuan C J-h, Ya L, Shao-hong C, et al. Construction and immunoscreening of CDNA library of Babesia microti. Int J Med Parasit Dis. 2013:40:130-4.

36. Luo YZ, Terkawi MA, Jia HL, Aboge GO, Goo YK, Cao SN, et al. A double antibody sandwich enzyme-linked immunosorbent assay for detection of secreted antigen 1 of Babesia microti using hamster model. Exp Parasitol. 2012;130:178-82.

37. Luo YZ, Jia HL, Terkawi MA, Goo YK, Kawano S, Ooka H, et al. Identification and characterization of a novel secreted antigen 1 of Babesia microti and evaluation of its potential use in enzyme-linked immunosorbent assay and immunochromatographic test. Parasitol Int. 2011;60:119-25.

38. Zhou X, Li SG, Chen SB, Wang JZ, Xu B, Zhou HJ, et al. Co-infections with Babesia microti and Plasmodium parasites along the China-Myanmar border. Infect Dis Poverty. 2013;2:24-30.

39. Snounou G, Viriyakosol S, Zhu XP, Jarra W, Pinheiro L, Rosario VED, et al. High sensitivity of detection of human malaria parasites by the use of nested polymerase chain reaction. Mol Biochem Parasit. 1993;61:315-20.

40. Wang G, Efstratiou A, Moumouni PFA, Liu M, Jirapattharasate C, Guo H, et al. Expression of truncated Babesia microti apical membrane protein 1 and rhoptry neck protein 2 and evaluation of their protective efficacy. Exp Parasitol. 2017;172:5-11.

41. Munkhjargal T, Aboge GO, Ueno A, Aboulaila M, Yokoyama N, Igarashi I. Identification and characterization of profilin antigen among Babesia species as a common vaccine candidate against babesiosis. Exp Parasitol. 2016;166:29-36.

42. Terkawi MA, Aboge G, Jia H, Goo YK, Ooka H, Yamagishi J, et al. Molecular and immunological characterization of Babesia gibsoni and Babesia microti heat-shock protein-70. Parasite Immunol. 2009;31:328-40.

43. Saeed Al, Sharov V, White J, Li J, Liang W, Bhagabati N, et al. TM4: A free, open-source system for microarray data management and analysis. Biotechniques. 2003:34:374-8.

44. Wang L, Feng Z, Wang X, Wang X, Zhang X. DEGseq: an R package for identifying differentially expressed genes from RNA-seq data. Bioinformatics. 2010;26:136-8

45. Wang J, Ying Y, Shen $\mathrm{H}$, Tao Q, Zheng Y, Li Q, et al. Dynamic transcriptomes identify biogenic amines and insect-like hormonal regulation for mediating reproduction in Schistosoma japonicum. Nat Commun. 2017;8:14693.

46. Goshima N, Kawamura Y, Fukumoto A, Miura A, Honma R, Satoh R, et al. Human protein factory for converting the transcriptome into an in vitroexpressed proteome. Nat Methods. 2008:5:1011-7.

47. Homer MJ, Aguilar-Delfin I, Telford SR, Krause PJ, Persing DH. Babesiosis. Clin Microbiol Rev. 2000:13:451-8

48. Rozej-Bielicka W, Stypulkowska-Misiurewicz H, Golab E. Human babesiosis. Przegl Epidemiol. 2015;69:489-94.

49. Leiby DA. Transfusion-transmitted Babesia spp.: Bull's-eye on Babesia microti. Clin Microbiol Rev. 2011:24:14-28.

50. Dantrakool A, Somboon P, Hashimoto T, Saito-Ito A. Identification of a new type of Babesia species in wild rats (Bandicota indica) in Chiang Mai Province, Thailand. J Clin Microbiol. 2004;42:850-9. 
51. Fell AH, Smith NC. Immunity to asexual blood stages of Plasmodium: is resistance to acute malaria adaptive or innate. Parasitol Today. 1998;14:364-9.

52. Zhou X, Li SG, Wang JZ, Huang JL, Zhou HJ, Chen JH, Zhou XN. Emergence of human babesiosis along the border of China with Myanmar: detection by PCR and confirmation by sequencing. Emerg Microbes Infect. 2014;3:e55.

53. Zhou X, Xia S, Huang JL, Tambo E, Zhuge HX, Zhou XN. Human babesiosis, an emerging tick-borne disease in the People's Republic of China. Parasit Vectors. 2014;7:509.

Ready to submit your research? Choose BMC and benefit from:

- fast, convenient online submission

- thorough peer review by experienced researchers in your field

- rapid publication on acceptance

- support for research data, including large and complex data types

- gold Open Access which fosters wider collaboration and increased citations

- maximum visibility for your research: over $100 \mathrm{M}$ website views per year 